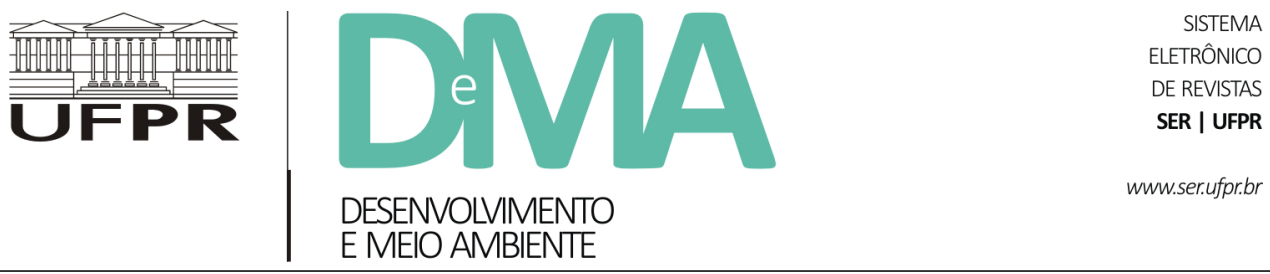

\title{
Tecnologia, imaginação e ecologia na obra de Murray Bookchin
}

\section{Technology, imagination and ecology in Murray Bookchin's Works}

\author{
Alysson Eduardo de Carvalho AQUINO ${ }^{1 *}$, Gilson Leandro QUELUZ ${ }^{1,2}$ \\ ${ }^{1}$ Programa de Pós-Graduação em Tecnologia e Sociedade (PPGTE), Universidade Tecnológica Federal do Paraná (UTFPR), Curitiba, PR, Brasil. \\ ${ }^{2}$ Departamento de Estudos Sociais (DAESO), Universidade Tecnológica Federal do Paraná (UTFPR), Curitiba, PR, Brasil. \\ *E-mail de contato: alysson.aquino@gmail.com
}

Artigo recebido em 11 de fevereiro de 2019, versão final aceita em 9 de outubro de 2019.

RESUMO: Este trabalho tem por objetivo apresentar algumas reflexões sobre tecnologia, imaginação e ecologia presentes na obra do pensador libertário estadunidense Murray Bookchin $(1921$ - 2006), idealizador da Ecologia Social - abordagem crítica que influenciou movimentos sociais de vários países. Inicialmente, trabalharemos a noção de imaginação técnica desenvolvida pelo autor e, junto dela, destacaremos a crítica da imagem sobre a técnica predominante na modernidade e na concepção de trabalho em Marx. Para Bookchin, o estudo das imagens técnicas possibilita perceber a presença tanto de "epistemologias da dominação" quanto de "liberação". Seu objetivo é investir na construção de uma perspectiva tecnológica vinculada aos ideais libertários e ecológicos. Em sua concepção, a construção de tecnologias libertadoras só é possível com a criação de instituições sociais emancipadoras e de uma sociedade que permita a liberdade. Assim, seu projeto visa confrontar radicalmente as tecnologias políticas. Nessa direção, ele também realiza uma crítica da lógica científica que constrói a crença na superioridade humana sobre a natureza. Em oposição, Bookchin tenta construir as bases de uma teoria que incorpore valores capazes de reelaborar a visão moderna da ciência e da técnica - considerando a fluidez da natureza e a natureza fluida da humanidade.

Palavras-chave: Murray Bookchin; tecnologia libertária; anarquismo; ecologia social; imaginação técnica.

ABSTRACT: This paper aims to expose a number of reflections about technology, imagination and ecology which are present in the works by Murray Bookchin (1921-2006), who has formulated the concept of Social Ecology - a critical approach that has influenced social movements in several countries. At first, we will discuss the notion of technical imagination developed by the author and alongside we will point out his criticism upon image over technics, which are prevailing in modernity and in Marx's conception of labour. According to Bookchin, 
the study of technical images allows to perceive the presence of "epistemologies of domination" as well as "liberation" ones. His goal is to invest in the construction of a technological perspective related to libertarian and ecological ideals. In Bookchin's conception, the construction of libertarian technologies is feasible only with the creation of social emancipatory institutions in a society plenty of freedom. Therefore, his project intends to radically confront political technologies. So, he also criticizes the scientific logic that inspires the belief of human superiority over nature. Against this idea, Bookchin tries to build the foundations of a theory that could incorporate moral values in order to reshape a modern insight of science and technics, taking into account the fluidity of Nature and the fluid nature of humankind.

Keywords: Murray Bookchin; libertarian technology; anarchism; social ecology; technical imagination.

\section{Introdução}

Este trabalho tem por objetivo apresentar algumas das reflexões sobre tecnologia, imaginação e ecologia presentes na obra do pensador libertário estadunidense Murray Bookchin (1921 - 2006), idealizador da Ecologia Social - abordagem crítica dos estudos ecológicos, que influenciou movimentos sociais de vários países. Deter-nos-emos especialmente, na análise da noção de imaginação técnica desenvolvida pelo autor e, junto dela, destacaremos a crítica da imagem sobre a técnica predominante na modernidade e na concepção de trabalho em Marx.

Murray Bookchin nasceu em 1921 no bairro do Bronx em Nova York, filho de judeus russos imigrantes. Durante sua juventude militou junto a grupos comunistas e, posteriormente, aproximou-se do pensamento anarquista. Entretanto, apesar de ter acolhido a tradição anarquista, nunca deixou de manter um intenso diálogo crítico com as ideias essenciais de Marx e com agrupamentos políticos de tendência marxista. Uma das características mais marcantes de sua vasta obra é a capacidade de articular teoricamente temáticas e reflexões advindas de áreas diversas e de variadas escolas filosóficas. Suas análises se amparam em um vasto leque cultural que compreende a tradição socialista e utópica ampliada, a filosofia grega, a antropologia, a teologia, a história da ciência, a ecologia e a biologia, dentre outras. Em suma, tratou-se de um pesquisador múltiplo, de larga erudição, comprometido com a transformação social e que, ainda hoje, influencia diversos movimentos sociais ${ }^{1}$ de vários países. Bookchin faleceu em 2006 em Burlington, nos Estados Unidos (Augusto, 2012)2.

$\mathrm{Na}$ introdução de The Ecology of Freedom: The Emergence and Dissolution of Hierarchy, de 1982, aquela que foi sua obra fundamental, Murray

\footnotetext{
${ }^{1}$ Acácio Augusto (2012) aponta essa influência em alguns movimentos sociais sul-americanos como, por exemplo, os anarquistas, que fizeram utilização do termo "anarquismo social" a partir dos anos 2000. Bookchin também estabeleceu longo diálogo com os movimentos verdes da Itália e Alemanha. Atualmente um dos mais importantes grupos de resistência ao Estado Islâmico, o PKK (Partidos dos Trabalhadores do Curdistão), que atua em Kobane - território turco -, também apresenta Bookchin como uma de suas principais influências. Janet Biehl, sua companheira e atual continuadora de sua obra, tem se apresentado internacionalmente na articulação de vários movimentos ecológicos.

${ }^{2}$ Para acessar a biografia completa de Bookchin recomenda-se a leitura da obra escrita por sua companheira Janet Biehl chamada Ecology or Catastrophe: The Life of Murray Bookchin (2015).
} 
Bookchin deixa explícita a importância de autores como Max Weber, Max Horkheimer, Theodor Adorno e Karl Polanyi em sua formação intelectual, quando problematiza questões em torno das formas sociais de dominação e sua relação com a crise da razão, da ciência e da técnica no mundo contemporâneo. Esses elementos se tornam alvos cada vez maiores da preocupação teórica e militante de Bookchin à medida que ele elabora suas críticas ao sindicalismo e se afasta desse tipo de prática política, passando a estudar o tema da ecologia e se aproximar da militância preocupada com a chamada crise ecológica. Bookchin partiu em sua trajetória das reflexões do marxismo tradicional e caminhou em direção à esquerda libertária, principalmente ancorada na tradição anarquista de Kropotkin. Dos autores e militantes anarquistas Bookchin incorporou em sua reflexão parte do estilo de pensar e analisar a política da tradição utópica.

Conforme aponta Santigo Juan-Navarro (2011), os militantes anarquistas dedicavam-se à leitura de utopias consagradas ao mesmo tempo que desenvolveram a prática de escrita de suas próprias utopias nas quais exerciam criativamente sua capacidade de planejamento da sociedade socialista imaginada. Nessas utopias eram comuns descrições de sociedades com características estéticas atraentes descritas como seres vivos e possuidoras de sensações próprias.

Ainda de acordo com Juan-Navarro (idem), os escritos utópicos se apresentam em duas categorias: uma descritiva, de características literárias; e outra empírica, que busca reformas e experiências radicais. Nelas, espaço e tempo se atravessam enquanto ingredientes básicos. Na perspectiva libertária, podemos apontar a existência de algumas tendências políticas do movimento que estimularam a escrita de utopias como, por exemplo, os mutualistas, os tolstoianos e os anarco-comunistas.

Através de assimilação ampliada de vários espectros do campo socialista, Bookchin investe em um tipo de análise preocupada em desvelar as múltiplas determinações presentes nas relações de interdependência entre os problemas ecológicos e os problemas sociais. Ganha corpo então sua principal tese - iniciada em artigos escritos desde a década de 1950 - de que as raízes dos problemas ecológicos só podem ser compreendidas a partir das raízes dos problemas sociais - aspecto pouco presente no debate ambientalista do período. Nessa direção, André Lemes da Silva (2007) comenta que em 1964, em Ecology and Revolutionary Thougth, Bookchin demarca sua posição pública em defesa de uma mudança revolucionária enquanto solução à crise ecológica.

Durante a década de 1950, Bookchin começa a se voltar para questões ligadas à crise do meio ambiente e sobre problemas relacionados à alimentação. Nessas publicações, estabelece a relação existente entre a contaminação ambiental e suas origens sociais, marcadas pela exigência de busca pelo lucro e competição capitalista. A década seguinte é marcada por trabalhos em torno da temática da dominação: do homem pelo homem e do homem pela natureza. Seus textos são ampliados para além da questão alimentar e abre-se um panorama para temas da degradação ecológica, da radiação, do estresse urbano e das lutas políticas. Os textos da década de 1960 mostram de forma marcante a perspectiva revolucionária e utópica de Bookchin. São apresentados manifestos de ecologia radical destacando suas posições de defesa da mudança radical social como solução à crise ecológica. 
No início dos anos de 1970 publica obras que discutiam a importância da temática ecológica e das energias alternativas para os movimentos progressistas. Nessa década, Bookchin demarca sua diferenciação em relação aos chamados "ambientalistas". Ainda durante 1970 funda o Institute for Social Ecology (ISE) - em Vermont, nos Estados Unidos - instituição que oferece cursos sobre ecofilosofia, teoria social, tecnologias alternativas. O ISE "foi pioneiro na exploração de meios ecológicos de produção de alimentos, como jardinagem orgânica, permacultura e tecnologias alternativas" (Lemes da Silva, 2007, p. 99). Em 1982 lança The Ecology of Freedom: The Emergence and Dissolution of Hierarchy, sua principal obra, em que Bookchin defendia a necessidade de se fazer uma ecologia social de fundo radical sob o prisma da liberdade.

Ao longo de sua vida Murray Bookchin criticou dois tipos de ecologismos em voga principalmente entre as décadas de 1970 e 1990: a) o pensamento ambientalista pragmático; b) o pensamento ambientalista místico e primitivista. Bookchin desejava construir uma perspectiva ecológica dissociada das propostas "naturalistas" que buscavam um modelo de intervenção puramente técnico para os problemas ecológicos e que eram defendidas pelos chamados "movimentos verdes" - rapidamente absorvidas pelo discurso capitalista. Ao mesmo tempo, a proposta bookchiniana também se distanciava das filosofias de tipo New Age e seus apelos irracionalistas, pensamento defendido por correntes filosóficas como as da Ecologia Profunda, Primitivismo, Gaia e etc. (Bookchin, 2011)

Conforme assinalado, apesar da verve crítica, Bookchin também estava interessado em propor alternativas de outra natureza para os problemas ambientais, além de renovar a própria tradição política libertária. Nessa direção elaborará o que denominou Ecologia Social, uma disciplina forjada a partir da conjunção dialética entre anarquismo e ecologia, a qual possui como principal pilar filosófico a relação indissociável entre sociedade e ecologia (Silva, 2007).

A tradição libertária, fonte de inspiração da Ecologia Social, trouxe suas contribuições, principalmente, a partir das propostas do mutualismo social e natural desenvolvidas por Kropotkin ${ }^{3}$. Desse anarquista russo, Bookchin tomou como fundamental a necessidade de se pensar a reconciliação entre a humanidade e a natureza, em um processo no qual o auxílio mútuo (ajuda mútua) exerce papel central na evolução natural e social. Outro importante elemento da tradição libertária presente em Bookchin é a crítica das hierarquias e a perspectiva de reflexão da possibilidade do desenvolvimento técnico ser realizado a partir de uma base social e produtiva descentralizada, através do modelo federativo proposto desde P. J. Proudhon.

Essa tentativa de construção de uma proposta ecológica libertária e radicalmente consistente demonstra o esforço desse pensador em tentar superar teorias que pensam o mundo a partir de uma lógica dualista de separação entre a humanidade e a natureza. Conforme discorre Bookchin:

Conocer el desarrollo de la dominación, la técnica, la ciencia, y la subjetividad - de esta última, tanto em la historia natural como em la historia humana - , es dar com lazos unificadores entre la naturaleza humana y la no humana”. (Bookchin, p. 11, 1999a).

\footnotetext{
${ }^{3}$ Sobre o pensamento de Kropotkin, ver: Morris (2018).
} 
A partir desse quadro sintético do contexto das reflexões de Murray Bookchin, bem como as bases filosóficas que acompanharam seu pensamento, pode-se dar continuidade neste trabalho discutindo mais profundamente suas teorizações sobre Ecologia, Tecnologia e Sociedade.

\section{Ecologia social-uma ecologia contra a dominação}

A Ecologia Social é uma ecologia fundada na ideia radical de liberdade e uma de suas noções mais importantes é a de que a dominação da natureza pelo homem possui estreitos vínculos com a dominação do homem pelo homem. Assim, caso queiramos pensar em outra relação com a natureza, é fundamental projetar utopicamente a construção de uma sociedade emancipada e livre baseada em princípios ecológicos. Para isso, Bookchin defende a importância do desenvolvimento de uma nova tecnologia que esteja em consonância com as dimensões humanas - diferentemente do que se observa no capitalismo onde o desenvolvimento tecnológico, muitas vezes, provoca a degradação dessas condições.

Nesse sentido, Bookchin entende que tentativas experimentais de pequenas instalações solares e eólicas, jardins orgânicos ou o uso de fontes naturais locais defendidas por muitos ecologistas são importantes, embora não suficientes. Segundo a Ecologia Social, a tecnologia deve ser estudada de uma maneira alargada, contemplando também aspectos políticos da organização social sob a qual ocorre seu desenvolvimento. Assim, essas novas tecnologias só fariam sentido se estivessem em íntima relação com práticas sociais que também buscam a emancipação como a democracia direta, a descentralização urbana, a autogestão, as formas comunais de vida social, etc. (Bookchin, 1999a). Trata-se de uma leitura que considera indissociável a análise dos artefatos tecnológicos de suas dimensões políticas.

Em vários momentos de sua obra, Bookchin estuda os fenômenos ambientais e tecnológicos dentro de um quadro de totalidade no qual não podem ser destacados apenas componentes individuais, sejam somente políticos ou somente tecnológicos. O autor chama a atenção para o fato de que em nada adiantará uma sociedade atingir apenas a descentralização, ou fazer isoladamente o uso de modelos de energia menos agressivos ou, ainda, reduzir a contaminação de suas águas. Nada disso pode por si só criar uma sociedade ecológica segundo a Ecologia Social. Menos ainda se obterá caso se adote a lógica dos "passos graduais", das pequenas melhoras. Ainda que essas ações carreguem boas intenções elas não passariam de resoluções parciais e pontuais dos problemas estudados, possuindo mais potência em seu aspecto educativo do que de enfrentamento. Segundo Bookchin, a sociedade capitalista contemporânea alcançou um caráter universal e global e, dessa forma, soluções parciais não passariam de cosméticos que ocultariam a verdadeira natureza da crise: a crise da própria sociedade capitalista.

Bookchin é direto quando aponta que as leituras parcializadas cumprem a função ideológica de distrair a opinião pública e a análise teórica aprofundada, capaz de problematizar a necessidade de mudanças sociais reais. Para Bookchin, quando combinadas em um todo coerente e sustentadas em práticas sociais radicais - como no caso da Ecologia Social -, as opiniões com essas características são capazes de fugir da tendência desmembradora do 
todo social e desafiar o status quo vigente. Nesse sentido, o projeto de uma ecologia da liberdade estaria associado à construção de uma síntese apoiada na história, no desenvolvimento das relações sociais, das instituições sociais, das tecnologias, dos sentimentos em transformações e das estruturas políticas. (Bookchin, 1999a).

Cabe dizer ainda outra especificidade da Ecologia Social: no lugar da crítica das classes tipicamente marxista - ou da contestação do Estado - marcadamente anarquista - ela prefere priorizar a crítica da hierarquia e da dominação, pois entende que mesmo uma sociedade sem classes ou supostamente libertária poderia ocultar a existência de relações hierárquicas, de dominação ou o próprio sentimento hierárquico. Bookchin entende hierarquia da seguinte maneira:

a los sistemas culturales, tradicionales y psicológicos de obediência y mandato, no solamente a los sistemas económicos y políticos a los cuales los términos "classe" y "Estado" se refieren más apropriadamente" [...] "yo aludo em cambio a la dominación del joven por el viejo, de mujeres por hombres, de un grupo étnico por outro, de "massas" por burócratas que juran hablar em sus "más altos interesses sociales", del campo por la ciudade, y em un sentido psicológico más sutil, del cuerpo por la mente, del espíritu por uma chata racionalidad instrumental, y de la naturaleza por sociedade y la tecnología (Bookchin, p. 18, 1999a).

Essa ideia, que vislumbra a superação dos sistemas hierárquicos e de domínio como a principal tarefa de transformação social a ser realizada, será um ponto articulador das reflexões que compõem os outros eixos propostos pela Ecologia Social. Tendo isso em vista, passaremos a outro ponto deste trabalho no qual serão apresentadas algumas reflexões específicas sobre técnica, tecnologia e ciência desenvolvidas na obra The Ecology Of Freedom.

\section{Imaginação técnica e imagens sobre a técnica: é possível projetar outra forma de pensar a tecnologia?}

Ao refletir sobre a técnica e a tecnologia no mundo contemporâneo, Bookchin (1999a) apresenta o que para ele se trata de um curioso paradoxo, comum nas reflexões sobre tecnologia: de um lado as promessas das inovações técnicas causam excitação e comoção geral, por outro lado, seus resultados ainda produzem desconfiança e certo descontentamento.

Por muito tempo a imaginação técnica celebrou como modelo a ser seguido as enormes plantas industriais com suas fábricas gigantescas e seus imensos contingentes de máquinas e trabalhadores. A nova maquinaria inventada foi saudada por vanguardas artísticas - como as do futurismo - e as utopias populares foram atravessadas por monumentais imagens tecnocráticas capazes de trazer resolução dos conflitos sociais. A percepção da técnica no imaginário social do século XIX e do XX foi, segundo Bookchin (1999), mais fetichista do que racional. Nem a catástrofe da Primeira Guerra Mundial foi capaz de acabar com o mito técnico, que passou a ser questionado, com maior vigor, somente a partir dos anos 1960 por movimentos ecológicos, pacifistas e antinucleares.

A partir desses questionamentos ganharam força debates como aqueles sobre tecnologia apropriada ${ }^{4}$, assinalando um crescente medo entre as pessoas de

\footnotetext{
${ }^{4}$ Para uma reflexão sobre tecnologias apropriadas ver: Dagnino et al., (2004).
} 
que, talvez, as escolhas sociais pudessem estar comprometidas com modelos destrutivos de produção em massa e com os problemas mundiais de contaminação ambiental. Bookchin vê nesses processos sintomas de que a humanidade parece sentir, às vezes não tão claramente, um aparente engano proporcionado pela própria tecnologia. Dialogando a respeito das dimensões envolvidas na dialética do esclarecimento presente na modernidade, aponta para a maneira como o conhecimento intuitivo foi renegado e deixado de lado na reflexão filosófica racionalista e instrumental responsável por fornecer as matrizes cognitivas hegemônicas de nosso modo de pensar a tecnologia e a natureza.

Para Bookchin a mentalidade moderna foi educada para compreender a sofisticação técnica enquanto sinônimo de "boa vida", vinculada à noção de um progressismo social que culminaria, inevitavelmente, na liberdade da humanidade. Entretanto, ao retornar, por exemplo, ao pensamento grego, o autor observa que a compreensão de "boa vida" no mundo helênico era bastante distinta dessa compreensão moderna. Em Aristóteles, "viver bem" implicava viver uma vida ética na qual os sujeitos estariam comprometidos não apenas com o bem-estar de sua família e amigos, mas também com o de sua pólis e de suas instituições sociais (Bookchin, 1999a; 1999b). Por sua vez, na modernidade, boa vida se associa ao conforto produzido pelo uso de novos artefatos tecnológicos. Desse modo, o conceito de "boa vida" foi destituído de seu aspecto comunitário.

Conforme assinala Bookchin (1999a), essa dicotomia entre a imagem moderna de uma vida materialmente abundante e o ideal clássico de uma vida baseada em limites pode ser equiparada à dicotomia entre as concepções modernas e clássicas de técnica. De acordo com ele, o mundo moderno hegemonicamente compreendeu a técnica simplesmente como um conjunto de matérias-primas, ferramentas, máquinas e mecanismos a serem utilizados na produção de algum objeto. Assim, o juízo de valor de uma técnica passou a estar associado e baseado em características como a eficiência, a habilidade e o custo, sendo este último o fator preponderante.

Na leitura de Bookchin, a concepção clássica de técnica (ou techné) teria um significado mais amplo. O importante não seria somente o "como" se produzia um valor de uso, mas também se questionava o "porquê" de se produzir. Assim, tratava-se de um marco ético, racional e social. Além disso, techné descreveria um espectro mais amplo da experiência de vida que a moderna palavra técnica. $\mathrm{O}$ que Bookchin pretende com essa reflexão não é repetir um modelo grego de organização social, mas demonstrar a existência de outras possibilidades de se pensar a técnica e com ela se relacionar. É defender um projeto de retomada das dimensões éticas na reflexão sobre a técnica.

Em conjunto com a imagem de técnica hegemônica na modernidade está amalgamada a uma compreensão de natureza que pressupõe que o homem deva dominá-la. Contrapondo-se a esse modelo de pensamento, Bookchin recorre aos movimentos libertários e estéticos do século XIX como exemplares da possibilidade de produção de imagens técnicas as quais destaquem a interação fecunda entre a arte da humanidade e as potencialidades da natureza. Todavia, vale ressaltar que Bookchin não nega a modernidade como um todo, mas apenas as visões dominantes nela existentes.

Para Bookchin, pensar as várias imagens técnicas é fundamental, pois elas demonstrariam potencialmente tanto a possibilidade de desenvol- 
vimento de "epistemologias da dominação" quanto de "epistemologias de liberação". Desse modo, o estudo das imagens técnicas não pode ser reduzido à análise das bases técnicas sobre as quais uma técnica se desenvolveu. Segundo o autor, as imagens hegemônicas da modernidade sobre a criação técnica se originam em epistemologias de poder e foram forjadas durante muito tempo. Além disso, não somente as imagens sobre a técnica nos revelam questões importantes a respeito da própria natureza da técnica, mas as visões sobre o trabalho e a própria compreensão moderna de matéria como fundamento inanimado e irredutível do ser nos indicam modos de pensar estruturantes do nosso modo de viver. Nessa perspectiva, é possível elaborar a crítica de uma compreensão quantitativa da realidade que é tomada como passível de ser medida e contada matematicamente e de maneira estritamente racionalizante. Nesse tipo de visão predominante há a ausência da ideia de espírito; vê-se assim a antítese da subjetividade humana, desprezada neste tipo de imagem da técnica (Bookchin, 1999a).

Para melhor compreender a discussão proposta sobre imaginação técnica vale realizar alguns comentários acerca dos estudos sobre imaginário social e a maneira como foram desenvolvidos dentro da tradição anarquista. Um dos principais pesquisadores do tema no campo libertário foi Eduardo Colombo (2002), anarquista e psicanalista argentino. Colombo discute que o conceito de "bloco imaginário" ou "imaginário social" faz alusão a respeito do funcionamento social a partir de uma série de ideias e valores organizados que tomam a forma de uma espécie de "campo de força", capaz de atrair e orientar diversos conteúdos advindos de diferentes representações (expressados em formas sociais, ideologias, mitos ou instituições). A consolidação desse universo pode representar a limitação para o pensamento e a ação. Entretanto, o imaginário social também conduz em si uma carga criadora baseada na própria realizar humana. Nesse sentido, Colombo afirma que os libertários insistem na capacidade simbólico-instituinte dos seres humanos, denunciando sua monopolização ou apropriação pelo poder político.

No campo libertário, o debate sobre imaginário social teve como um de seus expoentes Gustav Landauer (1870 -1919). Rafael Zillio Fernandes (2018), ao comentar sobre a filosofia de Landauer, discute o desenvolvimento do importante conceito de Volk (povo) trabalhado pelo anarquista alemão ao discutir sobre as diferenças entre Estado, nação e povo. Com forte influência do idealismo germânico, Landauer propõe que o Volk seria uma entidade de desenvolvimento "orgânico" existente de forma independente do aparelho de Estado. Tanto Estado quanto Nação seriam constructos sociais, porém a nação se distinguiria ao encorajar a autodeterminação dos povos (volks) e o ativismo social, enquanto o Estado traria necessariamente autoritarismo, escravidão e passividade. Para além das ideias de nação, Estado e povo, Landauer desenvolve uma terceira "entidade", Geist (Espírito), que não está presente no Estado, enquanto o Volk tem um "Espírito" que liga cada indivíduo à comunidade, uma espécie de legitimidade comunitária. Conforme explica Fernandes (idem), em Landauer o Volk pode ser tomado como uma unidade cultural e espiritual,

\footnotetext{
${ }^{5}$ El imaginario social é um texto de Eduardo Colombo que insere suas reflexões na tradição dos teóricos da escola antiautoritária ou institucionalista tais como, Castoriadis, Ansart, Lourau, Bertolo e outros.
} 
não uma estrutura política ou econômica, nem uma entidade biológica determinada por laços de sangue fixos e inalteráveis. Por sua vez o Geist não pode ser tomado enquanto mero produto ou reflexo do mundo material, mera "consciência" determinada pelo ser social e explicado em termos de relações técnico-econômicas, trata-se de uma unidade mais ampla.

A tomar como referências alguns dos constructos de Landauer, Eduardo Colombo (2002) falará sobre distintas formas de se pensar historicamente as paixões humanas: a primeira seria expressa no ensino escolar tomando-as como detritos do passado que foram deixados; a segunda seria a de tomar historicamente as forças que nos impulsionam capazes de ser concretizadas em nossos desejos e paixões. Colombo defende que as ideias são integradas na realidade cotidiana através de processos sociais nos quais as pessoas se envolvem. Desse modo, o imaginário social estabelecido pode ser rompido mediante a insurreição coletiva e as pessoas, através da fratura neste processo, podem se apropriar das ideias emancipadoras e convertê-las em realidade. $\mathrm{O}$ imaginário, como mundo de representações e crenças, é coletivo, não se desenvolve sozinho. Assim, os adeptos das concepções libertárias poderiam desenvolver dois processos que não são estranhos entre si: por um lado, o estímulo aos movimentos de discussão e difusão ideológica e, por outro, o vínculo dessas formas de pensamento aos processos e lutas sociais existentes.

Tendo como referência a tradição anarquista de pensamento sobre o imaginário social, Murray Bookchin almeja pensar uma perspectiva de sociedade orgânica, composta por um reino de imagens qualitativamente distintas e por outras formas de sensibilidade quanto à natureza e à técnica, em contrapartida à realidade moderna vivida de forma hegemônica. Para isso, elabora um percurso histórico que visita teoricamente diversos agrupamentos humanos e comunidades por todo o mundo. A partir da experiência dessas comunidades seria possível vislumbrar imagens da natureza muito distintas das vividas pelo sujeito moderno. A natureza, nesses grupos, é tomada como sagrada, utilizam-se terminologias e nomeações mais orgânicas, para citar alguns exemplos. Desse modo, esse olhar para a história pode nos servir de inspiração para a construção de outras imagens de técnica no mundo contemporâneo.

Bookchin investe também na tentativa de superação da comum imagem de que o trabalhador se apropria da natureza. Para ele, embora existam distinções entre a sociedade e a natureza, há também certo matrimônio entre a natureza e a humanidade, o que não dissolve a identidade das partes. Ao discorrer sobre a compreensão animista de natureza e sobre as imagens do trabalho, o autor argumenta que o trabalho já foi tido no imaginário social de determinados grupos como uma revelação, como uma realização, como uma sincronicidade entre sujeito e objeto. Somente tardiamente ele foi bifurcado em uma imagem postuladora da tirania do sujeito sobre o objeto. A imagem da mãe acariciando o filho seria, assim, mais evocadora do verdadeiro processo artesanal do que a imagem do ferreiro golpeando o ferro com brutalidade, típica das representações visuais e metafóricas sobre o trabalho.

Ainda de acordo com Bookchin (1974), a visão científica da realidade acabou por se estruturar em torno da proposição de que podemos interpretar o ordenamento do real em forma de uma lógica científica explicada a partir de rigorosos sistemas matemáticos. Essa visão de ciência nos faz crer em uma 
suposta superioridade humana sobre a natureza que acaba por nos afastar de nossas responsabilidades para com outros seres humanos, para com a sociedade e para com a própria natureza. Nesse sentido, parece estar presente em Bookchin a denúncia do afastamento da ciência para com a ética e a política.

O projeto político e filosófico de Bookchin (1999a) não busca retomar as inocentes metáforas, as técnicas mágicas, os mitos e cerimônias e a imaginação animista pura e simplesmente, mas pretende fazer uma revisão mais racional daquilo que foi produzido pela humanidade até o momento. Ele buscava desenvolver uma lógica de ciência diferente, entendida como mais orgânica e capaz de pensar valores da imaginação técnica e da natureza de outros períodos ou marginais para a mentalidade moderna e, desse híbrido, forjar outras imagens técnicas. A imagem da técnica moderna não pode, de acordo com ele, omitir a natureza fluida do mundo em que vivemos e a natureza fluida da própria humanidade. A imaginação da nossa época, atualmente limitada, deve ser capaz de abarcar o fluxo da vida, ser dialética e criativa.

Ao longo da obra de Bookchin, para além das influências propriamente libertárias, há o diálogo, sempre de maneira crítica, com outras de suas bases para a reflexão sobre tecnologia e imaginação. Neste sentido, ressalte-se a importância da reflexão sobre a tecnologia advinda da Escola de Frankfurt, especialmente aquela sobre racionalidade instrumental e modernidade proposta por Adorno e Horkheimer ou, ainda, a aguda exposição sobre a unidimensionalidade da sociedade tecnológica e o apagamento da imaginação em seu caráter emancipatório, ela- borada por Marcuse ${ }^{6}$. Outras fontes significativas de Bookchin são aquelas referentes aos autores com temáticas concernentes ao chamado campo de estudos em Ciência, Tecnologia e Sociedade (CTS). Podemos exemplificar com John F. Kasson e seu estudo sobre a relação entre tecnologia e pensamento republicano, inclusive sobre a liberdade imaginativa política, presente na obra Civilizing the Machine (1999) e o filósofo político Langdon Winner e sua crítica às concepções e observações que concretizam no imaginário social a ideia descontextualizada e determinista de tecnologia autônoma, ou seja, "aquela que de alguma forma está fora do controle da agência humana” (Winner, 1978, p. 17).

Também, gostaríamos de frisar que a visão de Bookchin apresenta interessantes convergências com outros pesquisadores contemporâneos do imaginário técnico e científico. Beatriz Sarlo (1997), por exemplo, em seu estudo sobre o imaginário técnico na Argentina das primeiras décadas do século $\mathrm{XX}$, demonstra a complexa e contraditória constituição do imaginário na modernidade periférica, em uma sociedade urbana, na cidade de Buenos Aires, que experimentava uma profunda transformação na qual a mudança tecnológica tem uma profunda ressonância cultural. Sarlo opta por problematizar o imaginário técnico hegemônico, demonstrando que as diferentes formas de apropriação e produção do conhecimento técnico científico poderiam significar, até mesmo, um esforço de modificação das hierarquias sociais. Neste sentido, ela argumenta como literatos como Roberto Arlt e Horacio Quiroga, centrais para a modernidade literária argentina, construíram pontes entre os intelectuais e as pessoas pobres

${ }^{6}$ Para uma reflexão sobre a Teoria Crítica da Tecnologia e seus enraizamentos na Escola de Frankfurt, ver: Feenberg (2010). 
valorizando como modernos os conhecimentos técnicos dos trabalhadores. Por outro lado, demonstra o entusiasmo das classes populares pelas revistas e jornais divulgadores de informações técnicas, que permitiam a reafirmação da importância do saber fazer e possibilitavam a compensação simbólica da ausência de acesso aos saberes escolarizados, sob a apologia entusiástica da invenção. Podemos dizer que Sarlo (1997) explicita as tensões entre processos de incorporação e contestação ao imaginário técnico-científico contemporâneo em um país periférico, possibilitando a percepção de uma história aberta onde a potencialidade emancipatória está sempre presente.

Por sua vez, Sheila Jasanoff (2015), pesquisadora do campo dos estudos CTS, propôs o conceito de imaginários sociotécnicos. Nele, a exemplo de Bookchin, ela constata a relação entre o imaginário e as relações de poder, refletindo sobre os diferentes padrões de valores morais que se conectam às novas invenções tecnológicas e novas ideias científicas, e as diferentes posições constitucionais que a ciência e a tecnologia ocupam na ordem política em diferentes contextos. Para Jasanoff (2015), o imaginário sociotécnico, apesar de geralmente se referir àquele hegemônico em uma nação, pode ser constituído a partir de diferentes atores sociais como corporações, movimentos sociais, indivíduos. Desta forma, uma sociedade pode conviver com uma multiplicidade de visões sobre ciência e tecnologia, que se se constituem em imaginários quando adotados mais amplamente por um setor da comunidade. Os imaginários sociotécnicos em sua pluralidade, para Jasanoff (2015), contêm não apenas concepções do que pode ser realizado pela ciência e pela tecnologia, mas, especialmente, o que a vida deve ou não ser, envolvendo uma visão ética, assim como para Bookchin, do que é bom ou mau socialmente.

Bookchin, em seu diálogo com as tradições utópicas, também defende que o pensamento especulativo, a imaginação, a arte e a intuição podem servir como fontes de conhecimento. Elas são passíveis de serem valorizadas tanto quanto o raciocínio indutivo dedutivo e a verificação empírica etc, - apesar de esquecidas pela ciência. A ideia de totalidade deveria estar presente em nossos métodos de interpretação e interação com mundo com a mesma intensidade e não serem escolhidas determinadas características em detrimento de outras.

Ao discorrer sobre o que chama de princípio federalista, Fernandes (2018) aponta que a tradição utópica e de pensamento sobre o futuro anarquista não deve ser tomada apenas como um modelo teleológico, mas sim enquanto um exercício de imaginação que tenta pensar a elaboração de cenários futuros baseados em lutas concretas do passado e do presente. Assim, os princípios desenvolvidos na tradição do pensamento e da práxis libertários se colocam como alternativas e inspiração para a reflexão acerca da organização política do espaço e da vida humana sob a perspectiva emancipatória e tendo a autonomia como horizonte de pensamento e ação.

\section{Matriz social da tecnologia e suas dimensões}

Ao refletir sobre o modo como pensamos a técnica e a tecnologia, Bookchin afirma que tão grave quanto a forma assumida pela mecanização do mundo é o fato de que em nossas vidas cotidianas não possamos distinguir o social do técnico. Diante dessa incapacidade, perdemos a habilidade 
de definir o que realmente é importante socialmente. Segundo ele, carecemos de uma noção de matriz social da tecnologia na qual todas as técnicas devem estar inseridas e em que o significado social da tecnologia passe a ser levado em consideração dentro de um quadro ampliado e não restrito apenas aos conflitos de ordem técnica. Para Bookchin (1986), o problema histórico da técnica está em como podemos absorver a técnica dentro de uma sociedade emancipatória.

Dessa maneira, os mais importantes problemas da técnica são suas vinculações com os ideais e as estruturas sociais de liberdade. Em princípio, uma técnica libertária se diferencia de uma técnica autoritária por algo mais que a escala de produção, o tipo de tamanho ou a forma em que se organiza o trabalho. Para Bookchin, é fundamental superar a metafísica dualista entre estrutura e superestrutura, devemos entender as estruturas políticas, pois estas podem ser mais técnicas que as próprias ferramentas e as máquinas (Bookchin, 1999a).

Para se postular a existência de uma tecnologia libertadora, pressupõe-se existência de instituições libertadoras, o desenvolvimento de uma sensibilidade libertária requer uma sociedade emancipada (Bookchin, 1984; 1999b). Nesse sentido, Bookchin defende a necessidade de lidarmos com a tecnologia de forma parecida com a que os grupos antinucleares estabelecem com os recursos energéticos, ou seja, devemos inserir no debate técnico questões de natureza ético-política. Isso quer dizer que devemos perguntar, a todo instante, se fábricas, minas, exploração agrícola de larga escala são desejáveis ou aceitáveis. Em caso de resposta negativa, podemos desenvolver alternativas ética e socialmente aceitáveis. Não se trata se lidarmos com os problemas ecológicos apenas como problema técnico ou admi- nistrativo, mas de verificar sua implicação e impacto social como ponto de partida (Bookchin, 1998).

Ao olhar para as sociedades que resistiram ao desenvolvimento técnico industrial, Bookchin irá ressaltar dimensões como a intensa vida familiar, o autocuidado, o mutualismo, a vivência comunitária. Aspectos aos poucos deixados de lado na sociedade industrial. Para ele, a técnica, no sentido estritamente instrumental da palavra, não dá conta de entender adequadamente as diferenças institucionais entre as várias organizações sociais de grupos com estruturas de ferramentas quase idênticas.

Todavia, mesmo uma discussão reduzida sobre problemas técnicos pode apresentar potencial construtivo. A partir dela, um considerável número de paradoxos podem ser explicitados. Paradoxos não capazes de resolução apenas por retórica política ou por fórmulas morais constantemente propostas por ideólogos. Nestes momentos é possível desnudar a natureza autoritária da tecnologia atual, colocar em cheque a ideia da neutralidade da tecnologia postulado de base aceito por diversos pensadores da tecnologia. Uma das objeções mais potentes seria a de criticar o ponto de vista funcional, o qual considera a técnica como sendo apenas o meio inanimado, sem vida, do metabolismo entre o homem e a natureza (Bookchin, 1998).

Levando em consideração essas questões e ao estudar o desenvolvimento técnico, nota-se que a fábrica primitiva introduziu como elemento fundamental não a abstração, a racionalização ou a objetivação do trabalho. Não foi agregado nenhum motor e nenhuma máquina ao já existente. $\mathrm{O}$ que realmente houve de novo foi que uma nova técnica suplantou a antiga: a técnica da supervisão, com a intensificação do processo de trabalho e a introdução do medo. Tal aspecto demonstra que a técnica 
não é um "fator natural", tal como não são naturais a agricultura e a alimentação tratadas com produtos químicos ou produzidas de forma sintética. Longe de ser mero dado pronto, a técnica constitui um dos mecanismos maleáveis que a humanidade possui. As instituições, os valores, os códigos culturais empregados pelos seres humanos são, segundo Bookchin (1998), mais reticentes à mudança do que, propriamente, os instrumentos que os materializam. A "neutralidade" da técnica sobre as relações sociais é apenas mais um mito. Ela, a técnica, mergulha num universo social de intenções, de necessidade, de desejos e de interações, conforme já discutido.

O elemento prejudicial da perspectiva da técnica atual é que ela não permite visualizarmos nossa capacidade de autodeterminação pessoal, como se fugisse de nossos controles. Mais ainda, produz-se um sentimento de autocompetência, que em geral é negado ao cidadão comum, nada se sabe a respeito do mundo inalcançável da tecnologia. A perspectiva de retomada do controle sobre a tecnologia reaparece, segundo Bookchin, sob o nome de "tecnologia popular" ou "alternativa". Nesses processos temos indícios da necessidade de operar uma mudança no sistema social atual. Estas técnicas alternativas forneceriam o contexto possível, e talvez histórico, para a mudança social. Elas permitiriam o florescimento de outras relações sociais, experimentadas enquanto realidade viva e concreta, tornando-se dispositivos educativos e comunitários que ensinam um modo de ver a política valorizadora da autodeterminação social (Bookchin, 1998).

Considerando a dimensão política da técnica, Bookchin discute que o elemento surpreendente do desenvolvimento social não é o surgimento de despotismo, mas sim a ausência dessa prática em vastas zonas do planeta. A prova da bondade pre- sente nas sociedades orgânicas pode ser vista em diversas culturas que não seguiram o caminho da estatização, da divisão de classes etc. Esses fatores possibilitariam afirmar as bases de uma tecnologia libertadora (Bookchin, 1986; 1999a; 1999b).

Bookchin faz considerações também sobre as relações existentes entre a destruição da experiência comunitária e o desenvolvimento da técnica contemporânea sob o capitalismo. Quando as restrições sociais baseadas na ética e nas instituições comunais foram demolidas ideológica e fisicamente, a técnica se tornou livre para seguir os ditames do interesse privado.

Para Bookchin (1984), o capitalismo subverteu uma dimensão fundamental da ordem social tradicional: a integridade da comunidade humana. Esse sistema social reduziu as relações entre indivíduos a relações entre comprador e vendedor, além de produzir a dissociação entre os espaços, tornando antagônica a agricultura em relação ao artesanato, o artesanato em relação à fábrica e a cidade em relação ao campo. O capitalismo invadiu e subjugou áreas da vida social que nenhum dos grandes impérios do passado havia conseguido penetrar.

Tendo isso em vista, surge como desafio intelectual a produção de modelos teóricos capazes de interpretar as novas possibilidades sociais abertas para a humanidade. Bookchin defende que somente a sensibilidade libertária possui elementos privilegiados para tal empreendimento. Caso não sejamos capazes de construir uma consciência articuladora da lógica social dos quadros técnicos, poderemos perder grandes chances enquanto assistimos à integração das tecnologias alternativas à lógica da sociedade repressiva e tecnocrática. 


\section{Crítica da concepção marxista da técnica e da natureza}

O empreendimento realizado por Bookchin visa ainda elaborar uma análise da técnica e das imagens que moldam sua forma e seu destino através do exame das ideologias em torno do trabalho. Para isso, volta-se para aquela que considera a forma ideológica mais sofisticada: a obra de Marx. Conforme já discutido, na mentalidade moderna o trabalho é tomado enquanto uma atividade abstrata, um processo distante das noções humanas de genuína autorrealização

A crítica de Bookchin a Marx aqui apresentada caminha em ao menos dois sentidos: o primeiro em torno da sua concepção de trabalho e o segundo sobre a imagem de natureza que o autor alemão tinha. Discutindo elementos da obra de Marx, Bookchin (1999a) compreende que o autor comunista toma o processo laboral como sendo estritamente um processo técnico.

De acordo com Bookchin, o vocabulário em torno da técnica é revelador e Marx estaria preso às prometeicas e burguesas imagens que prefiguram a busca pela liberação da natureza ${ }^{7}$. Apesar das referências que Marx fazia ao conceito de matrimônio entre a natureza e o trabalho, esse matrimônio seria do tipo visto no patriarcado, um matrimônio coercitivo no qual há o domínio de uma parte sobre a outra.

A crítica bookchiniana a Marx se desenvolve no seguinte sentido: Marx, em sua herança iluminista, estabelece a ideia de que a primeira natureza é um reino da necessidade, no qual as matérias-primas são escassas e o trabalho humano deve, de forma dificul- tosa, extrair, trabalhar e elaborar objetos úteis. De alguma forma, essa visão remonta ao mito bíblico do pecado original em que a primeira natureza é o reino do escasso e esse reino deve ser domesticado pelo trabalho. Esse tipo de concepção se encontra dentro do pensamento econômico do século dezoito, quando a economia adota um toque fatalista ao ser definida como o "estudo dos recursos escassos frente às necessidades ilimitadas" (Bookchin, 1999a).

Segundo Bookchin, o marxismo secularizou esse mito e o estendeu de modo que ele passasse a ser o quadro explicativo e abarcador do desenvolvimento de toda a história humana. Assim, a explicação do surgimento das classes, por exemplo, está no marxismo intimamente vinculada à necessidade de dominação da natureza e a requerida mobilização de uma mão de obra por um grupo privilegiado de dirigentes supervisores e exploradores.

$\mathrm{Na}$ Ecologia Social, defende Bookchin (1999a), a visão da primeira natureza não é mesquinha, nem intratável, mas fecunda e está marcada por uma riqueza cada vez maior de diferenciação, complexidade e formação dos diferentes nichos ecológicos. A oposição entre desejos insaciáveis e recursos limitados trazida da economia está implícita em Marx. Bookchin assinala que as necessidades estão vinculadas às condicionantes da sociedade e, portanto, são problemas sociais, não questões geofísicas ou de quantidade de população tal como problematizada na economia clássica.

Na perspectiva da Ecologia Social - em contraposição à visão marxista - a evolução natural não é apenas um reino da necessidade estreito e restrito tal como em Marx está designada a natureza. Ela

\footnotetext{
${ }^{7}$ Para outras visões sobre a questão da tecnologia, trabalho e natureza na obra de Marx, ver: Rosenberg (2006) e Dussel (1984).
} 
é vista como um desenvolvimento que mostra um esforço até a consciência e a liberdade. A natureza não exibe esse fim predeterminado, mas apresenta em si a potencialidade para alcançar a consciência e a liberdade. No lugar da reação passiva há a valorização da interação ativa e da intencionalidade como características presentes na natureza. Nesse sentido, abre-se a possibilidade de se pensar as contraposições existentes nas concepções de natureza consolidadas dentro da importante tradição marxista, mas que necessitam ser questionadas.

\section{Considerações finais}

Esse trabalho pretendeu introduzir algumas reflexões realizadas pelo influente pensador Murray Bookchin. Apesar da importância de sua obra para diversos movimentos sociais contemporâneos, Bookchin ainda é pouco estudado na universidade brasileira e muitos aspectos de sua original contribuição ainda devem ser explorados e, inclusive, criticados.

Dentre os aspectos críticos que podem ser apresentados, podemos sugerir alguns: a) narrativa de uma dinâmica histórica excessivamente calcada no binômio dominação-hierarquização que faz com que Bookchin deixe de lado, em vários momentos, dimensões como a luta de classes; b) a crítica aligeirada ao conceito de natureza em Marx e na ciência moderna; c) a pouca criticidade acerca do conceito do bem viver grego e sua adoção pouco problematizada; d) sua obra pouco levou em consideração a realidade dos países pobres; e) a adoção da tese do fim da sociedade industrial; dentre outras (Bookchin et al., 2003); f) a crença em uma suposta organicidade da sociedade vista em grupos mais diversos, sem critérios aprofundados; g) o abandono de uma perspectiva de luta classista e revolucionária - marcante em diversos anarquistas - em nome de uma tendência comunitarista que acabaria por "maquiar" essas relações (Corrêa, 2011); h) a crítica realizada por Hardt \& Negri (2003) acerca da estratégia "localista" - ao pensar a proposta de municipalismo libertário - de luta social desenvolvida num contexto de dominação capitalista global que repousa na dicotomia entre global e local, que acaba por admitir que o "global acarreta homogeneização e identidade indiferenciada, enquanto o local preserva a heterogeneidade e diferença" (Hardt \& Negri, 2003, p. 63).

Ao longo do trabalho pretendeu-se ressaltar as bases filosóficas da Ecologia Social, que vincula os problemas ambientais ao desenvolvimento de uma sociedade irracional e antiecológica. Esta sociedade é baseada em um sistema capitalista hierárquico, classista, competitivo e que fomenta a noção de mundo natural como "mera aglomeración de 'recursos' para la producción y el consumo humanos" (Bookchin, 1999a, p. 34).

Segundo seu idealizador, essa proposta ecológica é um projeto que implica um corte total com a sociedade de mercado, as tecnologias dominantes, o estatismo, as sensibilidades patricêntricas e prometeicas para com os humanos e a natureza, que foram absorvidas e realçadas pela sociedade burguesa (Bookchin, 2010).

Em sua perspectiva, princípios e valores das sociedades orgânicas - garantia dos meios materiais para a vida, compromisso com o usufruto, ética da complementariedade - são princípios que devem ser recuperados e se fazerem presentes em uma futura sociedade ecológica. Eles devem ser integrados à racionalidade, à ciência e, em grande parte, à técnica do mundo moderno. Todavia, devem ser redesenha- 
dos a fim de promover a integração da humanidade com a natureza.

Conforme apresentado, Bookchin discute o ocultamento do papel das técnicas, que se dão não apenas como simples expressão do desenvolvimento material das forças produtivas, mas como resultante de uma determinada maneira de organização econômica, política e social.

Dessa forma, faz-se urgente a mudança radical das atuais condições de exploração e dominação nas quais se encontra a humanidade e essa mudança deve atingir a maneira como intervimos na natureza. Em outras palavras, o capitalismo deve ser superado não só por perpetuar a exploração do homem pelo homem, mas também por estabelecer uma relação predatória do homem para com a natureza. O capitalismo produz uma forma de viver e de se relacionar que leva as sociedades humanas a um processo de autodestruição que acaba por se refletir na destruição da base natural da vida. Assim, a proposta de Bookchin se coloca no sentido de uma defesa do planeta e da continuidade da riqueza de vida na Terra. Essa defesa se dá a partir de uma crítica dos projetos de dominação que atravessaram a história da humanidade e se expandiram sob o capitalismo.

Por fim, ao expor sua proposta de ecologia social radical, Bookchin entende que esta não pode fechar os olhos para a problemática tecnológica. Nesse sentido, defende a bandeira do desenvolvimento de uma técnica ecológica. Para isso, a humanidade deve pôr em jogo tudo de si: trabalho, imaginação, ferramentas e seus desejos.

\section{Referências}

Augusto, A. Municipalismo libertário, ecologia social e resistências. Ecopolítica, 2, 64-98, 2011-2012. Disponível em: https://revistas.pucsp.br/ecopolitica/article/view/9076 Biehl, J. Ecology or Catastrophe: The Life of Murray Bookchin. New York: Oxford University Press. 2015.

Bookchin, M. Toward an Ecological Society. New York, Roots, 1974.

Bookchin, M. Seis tesis sobre municipalismo libertário. In: Bookchin, M, etal., La utopia és posible: experiencias posibles. Argentina: Tupac Ediciones, 1984.

Bookchin, M. Post-Scarcity Anarchism. Montreal, Black Roses, 1986.

Bookchin, M. Textos Dispersos. Lisboa: Socius, 1998.

Bookchin, M. La Ecología de La Libertad: La emergencia e la disolución de las jerarquías. Madrid: Nossa y Jara, 1999a.

Bookchin, M. Municipalismo libertário. São Paulo: NuSol/ Imaginário/Soma,1999b

Bookchin, M; Boino, P; Enckell, M. O bairro, a comuna, a cidade...espaços libertários! São Paulo: Imaginário, 2003.

Bookchin, M. Ecologia social e outros ensaios. In: Cavalcanti, M. J. (Org.). Rio de Janeiro: Achiamé, 2010

Bookchin, M. Anarquismo crítica e autocrítica: primitivismo, individualismo, caos, misticismo, comunalismo, internacionalismo, antimilitarismo e democracia. São Paulo: Hedra, 2011.

Colombo, E. El imaginario social, Nordan-Comunidad, Montevideo 2002.

Corrêa, F. Introdução. In: Bookchin, M. Anarquismo crítica e autocrítica: primitivismo, individualismo, caos, misticismo, comunalismo, internacionalismo, antimilitarismo e democracia. São Paulo: Hedra, 2011.

Dagnino, R.; Brandão, F C.; Novaes, H. T. Sobre o marco analítico-conceitual da tecnologia social. In: Tecnologia social: uma estratégia para o desenvolvimento. Rio de Janeiro: Fundação Banco do Brasil, p. 15-64, 2004.

Dussel, E. Filosofía de La Producción. Bogotá: Nueva América, 1984.

Feenberg, A. A Teoria Crítica de Andrew Feenberg. Brasília: CDS; UNB, 2010. 
Fernandes, R Z. O Princípio Federativo: um projeto político-espacial alternativo à lógica do Estado moderno. Bol. Goia. Geogr. (Online). Goiânia, v. 38, n. 2, p. 276-296, maio/ago. 2018. Disponível em: https://revistas.ufg.br/bgg/ article/view/54619

Jasanoff, S. Future Imperfect: Science, Technology and the Imaginaries of Modernity In: Jasanoff, S; Kim, S. (Orgs.). Dreamscapes of Modernity: Sociotechnical Imaginaries and the Fabrication of Power. Chicago: The University of Chicago Press, 2015.

Juan-Navarro, S. La ciudad anarquista americana: Utopías libertarias en el Nuevo Mundo. In: A.; Wagner, V. (Eds.). Disonancias interamericanas. Barcelona: Linkgua, p.37-57, 2011.
Kasson, J. F. Civilizing the Machine. New York: Hill and Wang, 1999.

Lemes da Silva, A. Da ecologia social à educação ambiental: as contribuições do pensamento libertário de Murray Bookchin. Rio Grande, Dissertação (Mestrado em Educação Ambiental) - FURG, 2007.

Negri, A.; Hardt, M. Império. Rio de Janeiro, Record, 2001

Rosenberg, N. Por Dentro da Caixa-Preta: Tecnologia e Economia. Campinas: Editora Unicamp, 2006.

Sarlo, B. La Imaginación Técnica. Buenos Aires: Nueva Visión, 1997.

Winner, L. Autonomous Technology. Cambridge, Massachusetts: The MIT Press, 1978. 